\title{
QUANDO E COMO USAR ENTREVISTAS POR E-MAIL: REFLEXÕES COM BASE EM PESQUISA SOBRE ASSEXUALIDADE
}

\author{
ELISABETE REGINA BAPTISTA DE OLIVEIRA ${ }^{1 *}$ \\ ORCID: https://orcid.org/0000-0003-4684-2337 \\ CLÁUDIA PEREIRA VIANNA** \\ ORCID: https://orcid.org/0000-0002-9366-4417
}

RESUMO: Com base em pesquisa sobre assexualidade, este artigo traz reflexões sobre os limites e as possibilidades do uso de entrevistas por e-mail. Com o objetivo de alcançar pessoas autoidentificadas como assexuais - em diferentes lugares do Brasil - a investigação que deu origem ao artigo utilizou o e-mail como ferramenta metodológica. Este artigo apresenta os desafios da realização de entrevistas por e-mail diante da ausência de pistas sociais como gestos, entonação de voz e linguagem corporal. Também expõe as vantagens ao possibilitar maior alcance geográfico dos sujeitos, ao permitir a participação de pessoas que - por diferentes motivos não concederiam entrevista presencialmente; e ao viabilizar o contato com uma autoidentificação nascida e difundida nos meios virtuais. Esses aspectos evidenciam o fortalecimento das tecnologias de informação e comunicação como instâncias socializadoras no processo de construção identitária na contemporaneidade e a contribuição do acesso à internet para o enriquecimento da pesquisa sobre assexualidade.

Palavras-chave: Pesquisa; Entrevistas por e-mail; Educação; Assexualidade; Diversidade sexual.

\section{WHEN AND HOW TO USE E-MAIL INTERVIEWS: REFLECTIONS BASED ON A RESEARCH ABOUT ASEXUALITY}

ABSTRACT: Taking a research about asexuality as a source, this article brings reflections on the limits and possibilities of using e-mail interviews as a methodological research tool. In order to reach self-identified asexuals who accepted to be interviewed - located in different regions, states and cities of

\footnotetext{
${ }^{1}$ Universidade de São Paulo, Faculdade de Educação,São Paulo, SP, Brasil.

"Doutora em Educação pela Faculdade de Educação da Universidade de São Paulo. Grupo de Estudos de Gênero, Educação e Cultura Sexual (Edges).

E-mail: < eoliver@uol.com.br >

${ }^{2}$ Universidade de São Paulo, Faculdade de Educação,São Paulo, SP, Brasil.

"*Professora Sênior do Programa de Pós-Graduação em Educação da Faculdade de Educação da Universidade de São Paulo. Grupo de Estudos de Gênero, Educação e Cultura Sexual (Edges).

E-mail: < cpvianna@usp.br >
} 
Brazil - the research that led to this article used e-mail as a tool. This article presents the challenges faced by e-mail interviews considering the absence of social clues - like gestures, voice intonation and body language. Additionally, the article also points out its advantages, such as allowing a greater geographic reach of the research subjects; making possible the participation of people who - for different reasons - would not agree to face-to-face interviews; and enabling the contact with a self-identification born and spread on the internet. These aspects highlight the strengthening of information and communication technologies as socialization agents in the process of identity construction in contemporaneity, as well as the contribution of the internet access to the enrichment of the research about asexuality.

Keywords: Research; E-mail interview; Education; Asexuality; Sexual diversity.

\section{INTRODUÇÃO}

Uma pesquisa, segundo Rosália Duarte, constitui “um relato de longa viagem empreendida por um sujeito cujo olhar vasculha lugares muitas vezes já visitados" (DUARTE, 2002, p. 140), ressaltando que o olhar diferente e original da/o pesquisador/a para o fenômeno bem como o modo como este se apropria do conhecimento a partir da experiência -, trará elementos pessoais ao processo da construção do conhecimento. Duarte reforça, neste sentido, a importância de narrar as etapas do processo que permitiu a realização do produto final. Refletir analiticamente sobre parte do caminho percorrido constitui o propósito geral deste artigo.

Buscamos, mais especificamente, examinar as possibilidades e os limites do uso do e-mail como ferramenta metodológica, conforme utilizada em uma pesquisa de doutorado, realizada no âmbito da educação, com sujeitos autoidentificados como assexuais, ou seja, por pessoas que não têm interesse por sexo e/ou por relacionamentos amorosos (OLIVEIRA, 2014). Considerado historicamente um distúrbio de ordem psicológica ou fisiológica na literatura médica, bem como um problema no senso comum, o desinteresse sexual e/ou amoroso - ou pelo menos uma parcela deste -, ganha novo significado, a partir do início do século XXI, com o surgimento e o crescimento de comunidades virtuais que reúnem membros em torno da identidade assexual. Neste novo paradigma, reforçado pelos assexuais, o desinteresse sexual e/ou amoroso tem sido compreendido como parte do espectro da diversidade sexual humana.

A sexualidade, neste artigo, é compreendida como uma "série de crenças, comportamentos, relações e identidades socialmente construídas e historicamente modeladas" (WEEKS, 2001. p. 43), 
sendo a assexualidade característica de uma configuração distinta de vivência da própria sexualidade, que não se fundamenta no pressuposto do interesse sexual, amoroso, universal e compulsório, como ocorre com as sexualidades mais conhecidas e estudadas. $\mathrm{Ou}$ seja, é uma forma de sexualidade caracterizada pelo desinteresse pela atividade sexual, podendo ser ou não acompanhada pelo desinteresse por relações amorosas. Como qualquer modo de viver a sexualidade, a assexualidade tem seus significados socialmente construídos no contexto da cultura, da história e das interações sociais. Essa abordagem contrasta com as perspectivas essencialistas presentes nos paradigmas sexológicos que dominaram os estudos da sexualidade até as últimas décadas do século XX (GAGNON, 2006). A pesquisa de doutorado da qual origina este artigo buscou refletir sobre o caráter social da sexualidade, especialmente, sobre as interseções entre a instituição escolar e as dimensões de sexualidade e gênero.

A pesquisa realizada constitui um produto da explosão discursiva sobre a assexualidade nos últimos anos - no Brasil e no mundo -, no contexto da problemática foucaultiana da articulação de discursos e da produção de saberes e sua relação com os poderes. Assim como coloca Michel Foucault (2005), a história da sexualidade é a história da produção discursiva sobre a sexualidade. Podemos situar essa explosão discursiva no contexto da América do Norte e Europa, tendo como marco a fundação da AVEN - Asexual Visibility and Education Network, em 2001, comunidade virtual norte-americana que impulsionou a discussão da assexualidade como sexualidade legítima e inspirou o surgimento de outras comunidades assexuais em diversos países, entre eles o Brasil. A emergência da militância assexual nas comunidades virtuais em conjunto com o florescimento da pesquisa científica sobre a temática foram os fatores que contribuíram enormemente para o alastramento da produção discursiva sobre a assexualidade em nível planetário. Juntamente com a AVEN, outras comunidades assexuais virtuais foram criadas, como por exemplo, a Livejournal Ace Community e a A-Positive, as quais também cresceram ao longo dos anos 2000. Porém, a AVEN continua a ser a comunidade com maior número de membros, a mais influente na mídia e nos eventos sobre sexualidade nos Estados Unidos, bem como a mais organizada, do ponto de vista político. Seus conteúdos são acessados e reproduzidos em diversos países, inclusive no Brasil. Importante também destacar a proliferação de diversos sites de encontros para pessoas assexuais que desejam relacionamentos amorosos, como por exemplo, Asexual Lesbians, Platonic Partners, Acebook, Asexual Pals, entre outros. 
As sexualidades são construídas pelos discursos, e não foi diferente com a assexualidade. Embora pessoas desinteressadas por sexo e por relacionamentos amorosos sempre tenham existido, foi somente a partir da proliferação dos discursos sobre a categoria assexual - no início do século XXI -, é que a assexualidade foi "fabricada" como categoria identitária, trazendo à tona indivíduos que passaram a se identificar como assexuais (GAGNON, 2006).

Nesse sentido, a própria realização da pesquisa de doutorado que fundamenta este artigo, assim como seus procedimentos metodológicos, faz parte do processo de visibilidade da assexualidade como categoria identitária, assim como fazem os demais discursos e dispositivos da sexualidade produzidos pela mídia, pelas instituições e por outras instâncias socializadoras.

Num mundo no qual os indivíduos são cada vez mais responsáveis por sua formação identitária, a criação e o desenvolvimento de tecnologias de informação e comunicação, ao longo de todo o século XX, certamente contribuíram para promover uma revolução nos modos de formação identitária na contemporaneidade. Essas tecnologias permitem ao indivíduo o acesso não só a um gigantesco e variado cabedal de informações, mas também a possibilidades de discussão, articulação e exploração de identidades, sobretudo as identidades marginalizadas, entre elas, as identidades sexuais não normativas. A possibilidade de questionamento, reformulação e ressignificação das identidades, à medida que o indivíduo tem acesso a novas informações ou vive novas experiências, conferem alto grau de reflexividade ao indivíduo contemporâneo.

Para Anthony Giddens, a reflexividade é uma "característica definidora de toda ação humana" (1991, p. 43). Com reflexividade, o autor quer dizer que "as práticas sociais são constantemente examinadas e reformuladas à luz de informações renovadas sobre essas próprias práticas, alterando, assim, constitutivamente seu caráter" (GIDDENS, 1991, p. 45). Ao mesmo tempo em que vivemos num mundo onde o conhecimento é reflexivamente aplicado, nunca estaremos seguros de que os conhecimentos são definitivos, ou seja, todo conhecimento é passível de revisão com a produção e circulação de novos conhecimentos e a articulação de novos discursos. As tecnologias de informação e comunicação tornaram esse processo muito mais rápido e abrangente na contemporaneidade. Isso é particularmente importante para as pessoas que se autoidentificam como assexuais, sujeitos em busca de uma identidade que vai se construindo à medida que novas experiências individuais são compartilhadas, novos estudos 
são publicados e novas discussões são promovidas nas comunidades virtuais e nos distintos grupos de discussão. Em um mundo amplamente globalizado e tecnologizado, a busca de si também envolve altos graus de reflexividade. Novas identidades, como a assexualidade, surgem a cada dia na rede mundial de computadores e, em pouco tempo, reúnem indivíduos de todo o mundo que entendem fazer parte daquele grupo. Identidades reais nomeadas nos meios virtuais e na militância assexual, adquirindo emergência social.

Embora a assexualidade ainda seja um tema pouco pesquisado nos programas de pós-graduação brasileiros, não poderíamos deixar de mencionar os dados colhidos no âmbito de uma pesquisa que trata das trajetórias sociais e reprodutivas de jovens brasileiros em três capitais do Brasil ${ }^{1}$ (HEILBORN et al., 2006), os quais fornecem pistas interessantes para o estudo da assexualidade. No universo juvenil da referida pesquisa (um total de 4.634 jovens de ambos os sexos, de 18 a 24 anos) foram apurados 588 jovens (12,5\% do total) que se declararam virgens, fenômeno denominado como iniciação sexual tardia por Bozon e Heilborn (2006, p. 186).

As análises das tabelas quantitativas da pesquisa de Maria Luiza Heilborn et al. trazem duas significativas indagações a esses/ as jovens: o motivo da não iniciação sexual, e o que as/os amigas/os pensam sobre sua virgindade. Mencionaremos somente os resultados mais relevantes numericamente às duas interpelações: $50 \%$ das mulheres e $34 \%$ dos homens responderam que ainda não tinham feito sexo por não terem encontrado a/ o parceira/ o ideal ou adequada/o; $38 \%$ das mulheres e $29 \%$ dos homens afirmaram que pretendem casar virgem. A pesquisa aponta, também, que $5 \%$ das mulheres e $6 \%$ dos homens assinalaram a opção Outro entre as alternativas oferecidas para ainda não terem iniciado a vida sexual. Quanto às opiniões de amigas/os sobre sua virgindade, $21 \%$ das mulheres e $50 \%$ dos homens afirmaram não conversar com os amigos sobre sua virgindade; $58 \%$ das mulheres e $27 \%$ dos homens responderam que o momento da primeira relação sexual é uma decisão unicamente sua.

Os resultados - marcados pelas diferenças de gênero parecem indicar a grande pressão sofrida pelas mulheres para que a iniciação sexual ocorra no contexto do relacionamento amoroso, daí, sua espera - ou busca - pela pessoa certa. Entre as/os que afirmaram querer manter a virgindade até o casamento, a porcentagem de mulheres também é maior. Cruzando dados da pesquisa, Michel Bozon e Maria Luiza Heilborn apresentam a hipótese de que a decisão pela virgindade até o casamento é fortemente marcada por convicções religiosas, principalmente para os homens. 
A respeito da interlocução com os pares sobre sua virgindade, o percentual de homens que não conversa com os amigos sobre esse assunto é muito superior ao percentual de mulheres, o que revela a pressão sofrida pelos homens para a iniciação da vida sexual, e o quanto a revelação da não iniciação aumentaria essa pressão. Segundo as/os pesquisadoras/es, "não conversar sobre o assunto é uma forma de resistir a tal pressão" (BOZON; HEILBORN, 2006, p. 187). Por último Bozon e Heilborn concluem que a justificativa de que a iniciação sexual é uma decisão individual constitui um argumento moderno para explicar uma conduta tradicional, considerando que o indivíduo da contemporaneidade tem autonomia para tomar suas próprias decisões. Independente dos motivos para o adiamento ou para a não iniciação sexual, o percentual de jovens virgens no grupo de idade 18-24 anos apurado pela pesquisa é considerável e traz desafios importantes para a educação, sobretudo, para a educação sexual escolar, além de trazer algumas pistas sobre os sujeitos assexuais.

Para relatar o caminho percorrido na pesquisa de campo, o artigo está organizado em־quatro partes. A primeira parte, a Introdução, contextualiza e historiciza a emergência da assexualidade como tema da pesquisa de doutorado, como resultado da explosão discursiva sobre esta temática no início do século XXI. A segunda parte traz o contexto metodológico que sinalizou a necessidade da utilização do e-mail como instrumento metodológico para a realização da maioria das entrevistas da pesquisa em questão, bem como os procedimentos metodológicos práticos empregados na pesquisa. A terceira parte traz reflexões relevantes sobre os limites e as possibilidades da utilização do e-mail para entrevistas na investigação acadêmica - sobretudo, em sua comparação com entrevistas presenciais -, por meio da análise de literatura pertinente. Para terminar, nas Considerações Finais, quarta parte, retomamos os caminhos trilhados a partir do estudo teórico do e-mail como instrumento metodológico para entrevistas em pesquisa, bem como ressaltamos a importância da utilização dos recursos tecnológicos da internet para a realização desta pesquisa, em particular.

\section{PROCEDIMENTOS METODOLÓGICOS PRÁTICOS EMPREGADOS NA PESQUISA}

A decisão de estudar as pessoas assexuais partiu da constatação da existência de diversos grupos e comunidades virtuais de brasileiros na internet - nas quais indivíduos autoidentificados como assexuais promovem discussões de temas pertinentes às suas vivências -, e também da escassez de estudos sobre essa categoria identitária 
sexual. O objetivo geral da pesquisa foi compreender as trajetórias de autoidentificação das assexualidades, a partir de entrevistas com informantes que se identificam dessa forma (OLIVEIRA, 2014). O foco instaurou-se nas interações sociais dos participantes durante os anos da educação básica, tendo como propósito entender o papel da escola nas trajetórias de descoberta, bem como conhecer as experiências dos informantes com a educação sexual escolar.

O projeto inicial da pesquisa era modesto: previa somente observação, descrição e análise das interações nas comunidades assexuais brasileiras, considerando que a assexualidade - como parte do espectro da diversidade sexual -, deveria estar contemplada pelos estudos de educação, do mesmo modo que outras sexualidades estavam sendo inseridas. O projeto original não previa entrevistas presenciais, por dificuldades que pareciam intransponíveis, como por exemplo, a pequena porcentagem de pessoas autoidentificadas como assexuais, sua existência sediada quase exclusivamente no meio virtual, sua distribuição esparsa pelo país, o estigma que conduz ao anonimato, o receio da patologização, entre outras.

Desde o levantamento prévio para o projeto, era possível observar que nas matérias da mídia sobre o tema, as fontes assexuais eram sempre anônimas e sem rosto, o mesmo ocorria nas comunidades que discutiam a assexualidade. A assexualidade era um conceito nascido na internet; apesar do vasto campo empírico, os indivíduos autoidentificados como assexuais faziam das comunidades virtuais seu habitat, como diz DeLuzio Chasin (2009), ocultando suas verdadeiras identidades e escondendo-se por trás de pseudônimos e avatares ${ }^{2}$ tornando sua identificação difícil, se não impossível. Parecia claro que seria dificultoso localizar informantes dispostas/os a se expor em uma entrevista sobre esta temática.

Conforme já mencionado, o fenômeno da assexualidade tem se propagado na internet, nos últimos anos, a partir da criação de comunidades virtuais que congregam pessoas que reiteram seu desinteresse pela prática sexual e/ou por relacionamentos amorosos. Apresenta-se como uma nova possibilidade no vasto espectro da diversidade sexual humana, não havendo ainda, pesquisas quantitativas que deem conta de mapear estatisticamente sua magnitude ou de apontar sua diversidade, principalmente porque se trata de um conceito ainda recente. Portanto, a abordagem qualitativa foi o caminho possível para a investigação da assexualidade no Brasil na pesquisa em questão. Trata-se de uma pesquisa exploratória, de natureza qualitativa e de perspectiva sociológica - inserindo- 
se nos estudos de diversidade sexual -, com o objetivo, como já mencionado, de compreender as trajetórias de autoidentificação de indivíduos assexuais, com destaque para suas interações sociais na escola, durante os anos da educação básica.

A pesquisa é exploratória no sentido de tratar de um fenômeno social que começou a ser estudado muito recentemente, na primeira década do século XXI. Toda literatura sobre a assexualidade majoritariamente produzida nos Estados Unidos, Canadá e Europa, - ainda é bastante descritiva, produzindo resultados ainda incipientes, preliminares, fortemente associados aos contextos culturais e sociais nos quais se inserem. Antônio Carlos Gil (2008) caracteriza a pesquisa exploratória como aquela que busca proporcionar maior familiaridade com determinado fenômeno - ainda pouco conhecido e pouco explorado -, com o objetivo de torná-lo mais explícito para futuras investigações. Portanto, a pesquisa em questão inserese nessa perspectiva. Sendo uma das primeiras pesquisas brasileiras a desenvolver um estudo empírico com sujeitos autoidentificados como assexuais, buscou-se colaborar para a construção de uma maior intimidade com o novo tema, contribuindo para a elucidação da emergência do fenômeno da assexualidade, bem como para a indicação de possíveis caminhos para novas explorações.

Um dos procedimentos de coleta de dados mais utilizados nas abordagens qualitativas - também selecionada para a pesquisa em questão -, é a entrevista. Svend Brinkmann (2008) argumenta que a entrevista na pesquisa qualitativa se tornou uma das práticas centrais na produção de conhecimento nas ciências sociais, embora tenha amargado um longo período de marginalização. A entrevista propicia um encontro de subjetividades entre pesquisador e informante, e não se trata de ferramenta de fácil utilização, como muitos querem fazer parecer. Rosália Duarte (2004) ressalta que ainda persiste, no meio acadêmico, a ideia de que a entrevista, enquanto instrumento de coleta de informações, é demais subjetiva, pouco confiável e utilizada com menor rigor do que outras ferramentas de investigação, o que é uma percepção equivocada desta ferramenta. Ao privilegiar a fala dos atores sociais, a entrevista "permite atingir um nível de compreensão da realidade humana que se torna acessível por meio de discursos, sendo apropriada para investigações cujo objetivo é conhecer como as pessoas percebem o mundo" (FRASER; GONDIM, 2004, p. 140).

A entrevista, na pesquisa qualitativa, direciona o foco para o discurso do entrevistado na elaboração de seu pensamento, exposição de suas ideias, a construção de sua narrativa, num trabalho 
que é relacional e dialético entre pesquisador e pesquisado, ambos se influenciando mutuamente, e que traz benefícios também para o entrevistado. Segundo Rosália Duarte,

Entrevista é sempre troca; [...] ao mesmo tempo em que coleta informações, o pesquisador oferece ao seu interlocutor a oportunidade de refletir sobre si mesmo, de refazer seu percurso biográfico, pensar sobre sua cultura, seus valores, a história e as marcas que constituem o grupo social ao qual pertence, as tradições de sua comunidade e de seu povo. Quando realizamos uma entrevista, atuamos como mediadores para o sujeito apreender sua própria situação de outro ângulo, conduzimos o outro a se voltar sobre si próprio; incitamo-lo a procurar relações e a organizá-las. (DUARTE, 2004, p. 220)

A pesquisa em questão utilizou roteiros semiestruturados de entrevista, os quais direcionaram o entrevistado a discorrer sobre os temas circunscritos no âmbito dos objetivos da investigação, porém, conferindo espaço para a espontaneidade nas respostas, permitindo que o entrevistado ressaltasse fatos ou eventos considerados mais importantes em sua narrativa.

Antes da etapa das entrevistas, foi necessária a criação de um canal de comunicação com pessoas autoidentificadas como assexuais em seu próprio habitat, ou seja, a internet. No primeiro semestre da pesquisa, em 2010, criamos o Blog Assexualidades, cujo objetivo era compartilhar com comunidades e indivíduos assexuais brasileiros resenhas da produção sobre a assexualidade publicada no exterior, uma vez que, na época, não havia literatura acadêmico-científica sobre o tema no Brasil. As resenhas - publicadas com periodicidade mensal, em português, e em linguagem não acadêmica -, acabaram por chamar a atenção do público interessado para a existência da pesquisa no Brasil. Com o tempo, pessoas assexuais de todo o Brasil passaram a escrever para os canais de comunicação do blog, para nos parabenizar por sua criação, agradecendo-nos pela realização da pesquisa e oferecendo compartilhar suas experiências por meio de entrevistas.

A criação de um canal de comunicação com possíveis alvos da pesquisa não constitui recurso metodológico inédito. $O$ pesquisador Fernando Seffner, em seu doutorado - que aborda as representações de masculinidade bissexual no Brasil - criou uma rede via postal, a Rede Bis-Brasil, denominada por ele de "operação estratégica e política que configurou um determinado recurso de método para esta pesquisa" (SEFFNER, 2003, p. 25). A rede cunhou um canal de comunicação com seu público-alvo, os homens bissexuais, produzindo, segundo o pesquisador, "um conjunto de verdades acerca da masculinidade bissexual brasileira" (SEFFNER, 2003, 
p.23), que devem ser compreendidas no contexto do dispositivo de produção utilizado como estratégia de pesquisa; ou seja, tivesse sido outro o dispositivo, também seriam outras as verdades.

Portanto, com a criação do Blog Assexualidades, a possibilidade - antes inexistente - de realização das entrevistas materializou-se em um número significativo de pessoas dispostas a contribuir com o estudo. Aos poucos, leitoras/es identificadas/os com a proposta do Blog Assexualidades passaram a fazer comentários às resenhas, ou entrar em contato conosco via e-mail. Recebemos grande quantidade de mensagens de leitoras/es durante os anos de desenvolvimento da pesquisa, muitas/os dos quais, se colocando à disposição para entrevistas. Diante deste novo quadro, era necessário decidir a forma como essas entrevistas seriam feitas.

A primeira intenção era fazer todas as entrevistas pessoalmente, mesmo que fosse necessário viajar para desempenhar esta tarefa. Isso se mostrou inviável diante da constatação de que os/as potenciais participantes localizavam-se em diferentes regiões, estados e municípios brasileiros. Outro fator que evidenciou a dificuldade de fazer todas as entrevistas face a face foi a resistência de algumas/ uns participantes em revelar-se pessoalmente. Uma jovem do Rio de Janeiro, por exemplo, perguntou se a entrevista não poderia ser feita por e-mail. O mesmo ocorreu com um jovem de Belo Horizonte, e outra, ainda, de Florianópolis. Algumas/uns informantes, mesmo morando em localidades próximas às pesquisadoras, também solicitaram que a entrevista fosse feita por e-mail. Portanto, consideramos necessário oferecer a todas/os participantes interessadas/os a opção da entrevista por e-mail - para que pudéssemos acolher todos os depoimentos, considerando que a diversidade das experiências traria maior riqueza à pesquisa. Uma vez divulgada esta possibilidade no Blog Assexualidades, o número de interessadas/os se multiplicou.

No final do processo, chegamos a 40 voluntários de todo Brasil dispostos a colaborar com a pesquisa. Destes, 8 participantes concordaram em conceder entrevistas aprofundadas presenciais, todas/os tendo como local de residência municípios próximos às pesquisadoras. Restavam, portanto, 32 informantes nas mais diversas regiões do país, as/os quais manifestaram seu desejo de conceder entrevistas por e-mail, o que era, para nós, uma forma ainda desconhecida de fazer entrevistas.

Após o contato inicial das pessoas interessadas em participar da pesquisa, respondemos agradecendo pelo interesse, listando os procedimentos necessários para participação, para obter sua concordância. Enviamos o Termo de Consentimento Livre e 
Esclarecido - TCLE, explicando que era uma exigência dos comitês de ética em pesquisa para garantir a confidencialidade das entrevistas e o tratamento ético das/os entrevistadas/os. Aos/às participantes por e-mail, oferecemos a opção de envio do TCLE pelo correio, ou, caso eles/as dispusessem de impressora, scanner ou câmera digital, poderiam mandar o documento assinado por e-mail. Àqueles que não dispunham de impressora, scanner ou câmera digital, pedimos um endereço de correspondência e enviamos o TCLE por correio, incluindo um envelope autoendereçado e pré-selado para devolução do documento assinado. Com estes procedimentos foi possível obter o TCLE assinado de todas as 32 pessoas entrevistadas por e-mail.

Ao tomarmos a decisão de acrescentar o e-mail como ferramenta de coleta de dados, ainda não tínhamos clareza de que modo equalizaríamos a análise das entrevistas por e-mail e das entrevistas aprofundadas presenciais do ponto de vista metodológico, considerando as diferenças entre as duas modalidades. Muitas inquietações se colocaram: seriam roteiros diferentes para as entrevistas presenciais e por e-mail? As entrevistas por e-mail seriam feitas em uma única etapa, ou em forma de diálogo com as pessoas entrevistadas? Como assegurar que as pessoas entrevistadas por e-mail estariam dispostas a escrever detalhadamente sobre suas experiências? Como analisar uma entrevista na qual não houve um encontro presencial entre pesquisadora e entrevistada/o, no qual teria sido possível observar o olhar, os gestos, o tom da voz, que trariam outras informações relevantes? Quais os cuidados na análise de cada tipo específico de entrevista?

Sabíamos ser necessário recorrer à literatura especializada para refletir melhor sobre essas diferenças e buscar uma forma de superar - ou, pelo menos, minimizar - possíveis disparidades na análise. Enquanto a literatura especializada sobre entrevistas presenciais em seus mais diversos aspectos -, era abundante, não localizamos no Brasil literatura que pudesse nos ajudar a refletir sobre os limites e possibilidades das entrevistas via e-mail na pesquisa acadêmica, sobretudo, no que se refere aos desafios decorrentes das distinções em relação às entrevistas presenciais. Buscamos tal suporte na literatura estrangeira, apresentada a seguir.

\section{POSSIBILIDADES E LIMITES DAS ENTREVISTAS PRESENCIAIS E POR E-MAIL}

As entrevistas por e-mail, segundo Jennifer Egan (2008) emergiram no final dos anos 1990 como um entre outros métodos qualitativos de pesquisa na internet. Enquanto a literatura metodológica sobre entrevistas qualitativas presenciais - também chamadas de 
face a face -, é numerosa, a literatura sobre entrevistas por e-mail apesar da consolidação das tecnologias mediadas por computador nas últimas décadas -, ainda é considerada escassa (MEHO, 2006; HUNT; MCHALE, 2007; BURNS, 2010). Na literatura específica, os autores costumam problematizar os dois tipos de entrevista, relacionando as vantagens e as desvantagens das duas modalidades, que devem ser analisadas criteriosamente antes da decisão por uma delas ou a combinação das duas. Márcia Fraser e Sônia Gondim (2004) ressaltam alguns aspectos das duas modalidades de entrevista, as presenciais ou face a face - e as entrevistas mediadas por recursos tecnológicos:

\footnotetext{
A primeira se refere àquela modalidade em que entrevistador e entrevistado se encontram um diante do outro e estão sujeitos às influências verbais (o que é dito ou perguntado), às não verbais (comunicação cronêmica - pausas e silêncios -, cinésica - movimentos corporais -, e paralinguística - volume e tom de voz), e às decorrentes da visualização das reações faciais do interlocutor. A segunda modalidade inclui as entrevistas feitas por telefone, por computador e por questionários, que também estão sujeitas às mesmas influências verbais e não verbais, mas de modo diferenciado, em especial quando não permitem a visualização das reações faciais do interlocutor. (FRASER; GONDIM, 2004, p. 143)
}

Raymond Opdenakker (2006) e Jennifer Egan (2008) ressaltam que a principal característica das entrevistas por e-mail é que são assíncronas, ou seja, independem de tempo e espaço - diferentemente das entrevistas síncronas, como a entrevista face a face, por telefone, ou até mesmo de outras formas de interlocuções mediadas por computador, como o Skype. ${ }^{3} \mathrm{Na}$ comparação, a entrevista face a face é caracterizada pela comunicação sincronizada no tempo e no espaço, ou seja, exige a presença do entrevistador e do entrevistado ao mesmo tempo no mesmo local geográfico, ou conectados a um canal de comunicação à distância, no caso das entrevistas por telefone ou Skype. As entrevistas por e-mail, por outro lado, são caracterizadas por comunicação assincronizada no tempo e no espaço, o que dispensa o agendamento de horário e local entre entrevistador e entrevistado. Uma das consequências desta diferença é que as entrevistas presenciais proporcionam informações para análise tão logo sejam realizadas e gravadas, enquanto as entrevistas por e-mail podem levar dias - até mesmo semanas -, para que os dados completos sejam disponibilizados pelo entrevistado ao pesquisador (MEHO, 2006). $\mathrm{Na}$ medida em que as entrevistas por e-mail rompem com as barreiras de tempo e espaço entre entrevistador e entrevistado, a interlocução pode se desenvolver ao longo do tempo, dentro da conveniência de cada um (SELWYN; ROBSON, 1998; OPDENAKKER, 2006; EGAN, 2008; BURNS, 2010). 
As entrevistas presenciais permitem sua realização em ambiente familiar ao informante - uma vez que, geralmente, o entrevistador deixa a cargo do entrevistado a escolha do local da entrevista -, de modo que este se sinta mais à vontade, com maior controle para compartilhar suas experiências (MEHO, 2006). Esta característica das entrevistas presenciais - apontada por Lokman I. Meho como vantagem sobre as entrevistas mediadas por tecnologias de comunicação - pode ser estendida também às entrevistas por $e$-mail, uma vez que o entrevistado provavelmente também estará em ambiente familiar ao responder às perguntas do entrevistador por meio da tecnologia.

Uma das vantagens oferecidas pelo uso de e-mail como ferramenta de pesquisa é o acesso a amostras em larga escala superando limites geográficos e fusos horários -, com baixos custos administrativos (BURNS, 2010). Com isto, pode-se entrevistar um número muito maior de sujeitos, de diferentes localidades e culturas do que permitiria a entrevista presencial. A comunicação via e-mail também permite ao pesquisador entrevistar indivíduos ou grupos com características específicas, muitas vezes inalcançáveis pela entrevista presencial, como por exemplo, executivos ocupados, celebridades, pessoas com algum tipo de deficiência ou doença, ou indivíduos localizados em regiões geograficamente distantes, ou ainda, pessoas vivendo em contextos politicamente instáveis e/ou socialmente perigosos (MEHO, 2006; EGAN, 2008).

Adicionalmente, Nigel Hunt e Sue McHale (2007) ressaltam que, enquanto as entrevistas presencias só podem ser realizadas uma de cada vez por um mesmo pesquisador, o recurso do e-mail permite a realização de vasto número de entrevistas simultaneamente, o que pode ser apontado como vantagem da última modalidade. No entanto, o que pode parecer a princípio uma vantagem, pode tornarse um problema quando o número excessivo de entrevistados gera uma quantidade de dados maior do que o pesquisador tem condições de trabalhar e analisar, podendo gerar frustração em entrevistados que não tiverem suas entrevistas utilizadas na pesquisa.

O fato de as entrevistas por e-mail já se apresentarem na forma escrita, também é apontado como vantagem pelos estudiosos, pois torna desnecessária a aquisição de equipamento de gravação, propicia ganho de tempo e elimina os custos financeiros da transcrição, bem como possíveis equívocos no processo (SELWYN; ROBSON, 1998; MEHO, 2006; HUNT; MCHALE, 2007; EGAN, 2008; BURNS, 2010). O material para análise é o texto produzido pelo próprio informante, o que apresenta a vantagem de ser construído conforme o fluir de sua própria articulação, e também a desvantagem de ser o 
único conjunto de dados para análise, desprovido de outras fontes de observação por parte do pesquisador (MEHO, 2006). Ademais, as entrevistas por e-mail eliminam a necessidade de despesas com transporte, alimentação e estadia do pesquisador, entre outras, muitas vezes, necessárias para a realização das entrevistas presenciais (MEHO, 2006; HUNT; MCHALE, 2007; EGAN, 2008; BURNS, 2010).

Uma desvantagem das entrevistas por e-mail - bem como de outras modalidades mediadas pelo uso do computador -, é que exigem, tanto do entrevistado como do entrevistador, habilidades no manejo das tecnologias de comunicação e informação (MEHO, 2006; EGAN, 2008), além de só poderem ser realizadas com a população que tem acesso à internet, o que pode imprimir um recorte de idade, renda, gênero e raça, por exemplo, restrito à faixa da população que tem acesso à internet (SELWYN; ROBSON, 1998; EGAN, 2008). As entrevistas por e-mail - vistas por Jennifer Egan (2008) como antidemocráticas, por serem restritas a determinado segmento populacional -, são vistas por Lokman Meho (2006) como modalidade que favorece a democratização e a internacionalização da pesquisa científica, uma vez que têm o potencial de alcançar sujeitos que não seriam atingíveis pela entrevista presencial.

Como mais uma desvantagem das entrevistas por e-mail, Neil Selwyn e Kate Robson (1998) apontam a efemeridade deste tipo de comunicação, o que pode comprometer sua eficácia como ferramenta de pesquisa. Mensagens por e-mail podem ser facilmente apagadas e descartadas, portanto, a entrevista pode ser perdida no processo. Lokman Meho (2006) acrescenta que, durante o período da entrevista, o entrevistado pode mudar de endereço eletrônico, ou de provedor de internet e não avisar ao pesquisador, que perderá o contato, e por consequência, a entrevista.

Outra desvantagem, apontada por Raymond Opdenakker (2006) - e corroborada por Neil Selwyn e Kate Robson (1998), Lokman Meho (2006) e Nigel Hunt e Sue McHale (2007) -, é que as entrevistas por e-mail não oferecem possibilidade de se captar as sutilezas da comunicação não verbal, denominadas pistas sociais pelo pesquisador. As pistas sociais - como, por exemplo, os gestos, a entonação da voz e a linguagem corporal -, oferecem ao entrevistador muitas informações adicionais, além de permitir maior contato com os sentimentos, crenças e valores dos entrevistados. Elementos tácitos da comunicação face a face - que podem ser relevantes -, são perdidos pela falta de contato pessoal. No entanto, Raymond Opdenakker ressalta que nem sempre essas pistas sociais são 
importantes para uma pesquisa. Nos casos em que a entrevista é feita com um especialista em algum tópico, somente como fundamentação para a análise das entrevistas com os principais sujeitos de uma pesquisa, as pistas sociais tornam-se menos importantes. Quando a entrevista é feita diretamente com o sujeito da investigação, o qual, em sua especificidade é insubstituível, as pistas sociais tornam-se fundamentais para uma melhor apreensão daquilo que se quer saber.

Em outra perspectiva, Lokman Meho (2006), Nigel Hunt e Sue McHale (2007) destacam que, justamente por não se tratar de uma entrevista face a face, a entrevista por e-mail pode eliminar - ou, ao menos, reduzir -, problemas relacionados a diferenças de pertencimento racial, escolaridade, classe social, gênero, deficiências, entre entrevistado e entrevistador, as quais podem interferir no sucesso da entrevista. Heloisa Martins ressalta que, na interação presencial entre entrevistador e entrevistado não é possível subestimar a influência "da história biográfica, da educação, interesse e preconceitos do pesquisador" (MARTINS, 2004, p. 292), o que torna a relação entre as partes não somente social, mas também política. Esse fator pode ser reduzido na entrevista por e-mail. Meho também lembra que a entrevista por e-mail pode alcançar entrevistados tímidos, introvertidos, que teriam dificuldade em expressar-se em uma entrevista presencial, mas sentem-se mais confiantes com a entrevista por e-mail.

Do ponto de vista do entrevistado, a entrevista por e-mail confere maior grau de anonimato do que uma entrevista presencial, embora não o seja (EGAN, 2008). A sensação de anonimidade pode encorajar o informante a ser mais aberto, espontâneo e desinibido em suas respostas escritas, de um modo que não seria, caso a entrevista fosse presencial (HUNT; MCHALE, 2007; EGAN, 2008). Este pressuposto da anonimidade, segundo Lokman Meho (2006), pode explicar por que alguns informantes estão mais dispostos a conceder entrevista por e-mail do que presencialmente. Por outro lado, é mais frequente nas entrevistas por $e$-mail-em comparação com as entrevistas presenciais -, que alguns entrevistados desistam da participação no meio da entrevista, sem avisar o entrevistador, ou mostrem-se hostis ao pesquisador, quando se sentem pressionados a responder. Neste caso, o entrevistador deverá tomar uma decisão ética sobre a utilização ou não do material incompleto (HUNT; MCHALE, 2007). Raymond Opdenakker (2006) observa também que, ao contrário da entrevista face a face - na qual o entrevistado pode sentir-se constrangido em responder alguma pergunta de forma socialmente indesejável, por assim dizer, buscando atender às expectativas do entrevistador 
-, a entrevista por e-mail reduz essa possibilidade. Por outro lado, a espontaneidade oferecida pela entrevista face a face é perdida na entrevista por e-mail (EGAN, 2008).

Um cuidado importante a ser considerado nas entrevistas por e-mail, ainda segundo Opdenakker (2006), é que cada pessoa tem um estilo próprio de se expressar. O entrevistador deverá se familiarizar com o estilo de escrita do entrevistado, de modo a captar as mensagens contidas nas entrelinhas, o que pode ser bastante difícil tendo-se como base somente o texto escrito. Além disso, o fator que parecia uma vantagem inicial das entrevistas por e-mail - a economia de tempo -, pode se revelar falso, considerando que em uma entrevista assíncrona, o entrevistado pode levar dias, ou até semanas para responder as perguntas. Isso aumenta o risco de o entrevistado perder o foco ou o interesse pela entrevista no processo (HUNT; MCHALE, 2007).

Lokman Meho (2006) ainda lembra que, ao passo que muitos indivíduos têm dificuldade com a expressão escrita - o que pode confundir o entrevistador em sua tentativa de compreender o que o entrevistado quis dizer -, outros se expressam com mais eficiência na forma escrita do que na expressão oral. $\mathrm{Na}$ entrevista por e-mail, o entrevistado tem tempo para refletir, pesquisar e construir sua resposta, sem que o entrevistador conheça o processo de formulação de sua escrita (OPDENAKKER, 2006; EGAN, 2008). Nigel Hunt e Sue McHale (2007) lembram que nas entrevistas por e-mail tanto o entrevistado como o entrevistador têm maior tempo para refletir sobre o que foi dito; por estar na forma escrita, ambos podem retomar qualquer parte da entrevista no texto antes de prosseguir com o diálogo, o que é mais difícil na entrevista presencial. Em relação à profundidade das interações entre pesquisador e entrevistado, segundo Kay Cook (2008), entrevistas aprofundadas são aquelas

[...] nas quais os participantes são encorajados a falar detalhadamente sobre o tópico em investigação, sem que o entrevistador tenha que interrompê-lo com perguntas curtas e focadas. O pesquisador não precisa preparar uma lista de perguntas muito abrangente. [...] As entrevistas aprofundadas são adequadas para a coleta de dados em diferentes tipos de metodologias [...] e são frequentemente usadas como método único e coleta de dados. (COOK, 2008, p. 422, tradução nossa).

Portanto, para atingir o mesmo nível de detalhamento de uma entrevista aprofundada presencial, uma entrevista aprofundada por e-mail pode exigir múltiplas trocas de e-mail entre entrevistador e entrevistado, durante longo período de tempo, por ser uma interação assíncrona, na qual as duas partes podem levar um tempo indeterminado entre perguntas e respostas. A interação presencial facilita a tarefa de empreender entrevistas aprofundadas. 
Edgar Burns (2010) argumenta que as tecnologias emergentes de comunicação não diminuem a importância das formas mais tradicionais de coleta de dados em pesquisas qualitativas, mas enriquecem o leque de ferramentas investigativas disponíveis para a pesquisa social na atualidade. Edgar Burns (2010), Nigel Hunt e Sue McHale (2007) ressaltam, ainda, que as entrevistas por e-mail podem ser utilizadas como modalidade não exclusiva de coleta de dados, ou seja, podem ser empregadas como complementação a outras formas de entrevistas, como as entrevistas presenciais, por exemplo.

Após a reflexão cuidadosa sobre as questões colocadas por tantas autoras e autores que refletiram sobre os limites e possibilidades das entrevistas por e-mail, comparando-as com as entrevistas presenciais, decidimos utilizar as duas modalidades de entrevistas em nossa pesquisa sobre a assexualidade, o que exigiu atenção redobrada na análise, uma vez que seria necessário, de alguma forma, equalizar as duas modalidades. ${ }^{4}$ A pesquisa em questão, portanto, utilizou as entrevistas por e-mail como forma de reunir mais elementos para a análise, como complemento às experiências trazidas pelas entrevistas presenciais.

Considerando que o número de entrevistas por e-mail, em nossa pesquisa, era quatro vezes superior ao número das entrevistas presenciais, concluímos que seria inviável gerenciar tamanha quantidade de entrevistas, se tivéssemos que fazer troca de mensagens por e-mail por estendido período de tempo. Nesse sentido, estabelecemos que as entrevistas presenciais seriam entrevistas aprofundadas, e as entrevistas por e-mail seriam feitas em uma única etapa de perguntas. Deste modo, foram enviadas as perguntas aos participantes, que as responderam de uma única vez, sendo que entramos em contato posterior somente quando percebemos que o entrevistado não tinha compreendido alguma pergunta. Dessa forma, realizamos nosso trabalho de campo, o qual conseguiu alcançar 40 entrevistados, moradores de 4 regiões, 13 estados e 31 municípios brasileiros. ${ }^{5}$

\section{CONSIDERACִ̃̃ES FINAIS}

Os dois principais fatores que apontaram para a necessidade da utilização de ferramentas tecnológicas para a realização do trabalho de campo da pesquisa com os assexuais foram, primeiramente, o fato de a comunidade assexual brasileira - assim como os indivíduos que nela interagem -, estar consolidada majoritariamente no ambiente virtual. Mesmo os entrevistados presenciais, em sua maioria, souberam da pesquisa pela internet, principalmente pelo Blog Assexualidades. Dificilmente alguém se identificaria como assexual não tendo 
tido acesso ao conceito de assexualidade, nascido e propagado no ambiente virtual. O segundo fator - a impossibilidade da realização de entrevistas presenciais com os muitos voluntários espalhados por diversas regiões, estados e municípios brasileiros -, também indicava a necessidade de pensarmos em alternativas. $\mathrm{O}$ e-mail demonstrouse uma ferramenta utilizada por todos os entrevistados, o mesmo não ocorrendo com outras formas de comunicação via computador, como o Skype, por exemplo. Sabemos que este recorte - acesso à internet -, certamente imprime determinadas características aos entrevistados, seja de renda, faixa etária, escolaridade e raça/etnia, abrangendo somente a parte da população que tem acesso digital.

Um ponto importante, observado nas entrevistas por e-mail, é que os entrevistados se mostraram mais objetivos em suas respostas, mantendo-se dentro dos limites das perguntas. Nas entrevistas face a face, existe uma grande probabilidade de divagação do informante - e até mesmo do entrevistador -, dependendo do rumo do diálogo e de seu grau de informalidade. Observamos isso nas entrevistas presenciais aprofundadas. Dos oito participantes presenciais, três concederam a entrevista em 1 hora, e cinco levaram até 2 horas para elaborar suas respostas. A diferença de tempo pode estar associada à quantidade de informações, ao nível de profundidade dos relatos, à forma de elaboração do pensamento e à expressão oral de cada informante.

$\mathrm{Na}$ análise geral do material de campo, buscamos levar em conta todos os fatores elencados sobre as duas modalidades na literatura especializada. Basicamente, na pesquisa, a característica principal das entrevistas presenciais é que estas ofereceram um panorama geral da vida do entrevistado, abrangendo, de modo mais profundo, o processo de autoidentificação da assexualidade e seus desdobramentos no contexto mais amplo da biografia dos indivíduos. Nesse sentido, o entrevistado presencial discorreu, em ordem cronológica, sobre sua infância, adolescência, vida adulta, até o momento da entrevista, situando suas percepções sobre sua autoidentidade assexual nos espaços sociais dos quais fez e faz parte. Os entrevistados por e-mail relataram de modo mais direto seu processo de autoidentificação, não necessariamente detalhando os desdobramentos desse processo ao longo de suas vidas. Porém, alguns entrevistados por e-mail foram surpreendentemente minuciosos em seus relatos, aproximando-se do detalhamento oferecido pelos entrevistados presenciais. Alguns entrevistados por e-mail mencionaram que o exercício de escrever sobre si foi muito positivo, pois antes nunca tinham pensado sobre sua trajetória de autoidentificação da assexualidade; escrever sobre esse aspecto de sua sexualidade ajudou-os a organizar seus pensamentos e lembrar-se de episódios importantes do percurso. 
Este estudo também evidenciou o fortalecimento das tecnologias de informação e comunicação - sobretudo a expansão do acesso à internet - como instâncias socializadoras que competem com a família e a escola no processo de busca identitária na contemporaneidade. As pessoas entrevistadas conheceram o conceito de assexualidade e se identificaram com o mesmo em suas interações na internet, meio que se mostrou imprescindível para a manifestação da assexualidade, ainda que esse acesso seja restrito em nosso país. Ou seja, pessoas que poderiam se identificar como assexuais nunca ouviram falar de assexualidade, por não terem acesso à internet. Este constitui um dos limites das comunidades virtuais: o acesso às tecnologias de informação e comunicação ainda não é universal; os grupos que têm acesso pertencem a determinadas categorias de nacionalidade, classe, raça, idade, gênero, escolaridade, entre outras. $\mathrm{O}$ sujeito assexual que interage no mundo virtual é, quase por definição, o indivíduo bricoleur, conforme definição de Danilo Martuccelli (2002), pois se mostra autônomo e ativo em sua busca identitária. Graças ao surgimento das comunidades virtuais, assexuais do mundo todo passam a situar seu modo de viver a sexualidade como uma característica de si, não mais relacionada à patologia.

Em relação aos resultados de campo, nossa ideia inicial era utilizar os conteúdos das entrevistas presenciais como fonte principal, utilizando as entrevistas por e-mail como complementares, como fontes de apoio. Mas diante da riqueza de todas as entrevistas, decidimos organizar um capítulo da tese com as biografias dos entrevistados presenciais para oferecer um panorama geral de suas trajetórias e de como a autoidentificação como assexuais se insere em seus percursos. As 32 entrevistas realizadas por e-mail foram somadas às entrevistas presenciais, na análise desenvolvida, com o objetivo de captar similaridades, diferenças, contrastes, aproximações, distanciamentos, consonâncias e dissonâncias das experiências de todos os participantes.

Para finalizar, afirmamos que as entrevistas por e-mail enriqueceram nossa pesquisa em formas que não poderíamos prever. As experiências compartilhadas pelos entrevistados trazem a ampla diversidade de vivências assexuais, marcadas pela rica diversidade cultural e regional do país, conferindo caminhos para novas explorações nesse campo. Em um momento histórico em que as tecnologias de informação e comunicação se tornaram tão relevantes nas interações sociais, o e-mail constitui ferramenta útil à pesquisa acadêmica, que deve se atualizar em conformidade com os canais e recursos disponíveis em nossa era. 


\section{REFERÊNCIAS}

ASSOCIAÇÃO BRASILEIRA DE LÉSBICAS, GAYS, BISSEXUAIS, TRAVESTIS E TRANSEXUAIS. Manual de Comunicação LGBT. MARTINS, Ferdinando; ROMÃO, L.; LINDER, L.; REIS, T. (org.). Curitiba: Ajir Artes Gráficas e Editora, 2010. Disponível em: http://www.abglt.org.br/docs/ManualdeComunicacaoLGBT.pdf. Acesso em: 24 abr. 2013.

BOZON, M.; HEILBORN, M. L. Iniciação à sexualidade: modos de socialização, interações de gênero e trajetórias individuais. In: HEILBORN, M. L.; AQUINO, E. M. L.; BOZON, M.; KNAUTH, D. R. (org.) O aprendizado da sexualidade - reprodução e trajetórias sociais de jovens brasileiros. Rio de Janeiro: Editora Fiocruz/Garamond, 2006.

BRINKMANN, S. History and Epistemologies of Interviewing. In: GIVEN, L. M. (org.) The Sage Encyclopedia of qualitative research methods. Volumes 1 \& 2, Los Angeles, London, New Delhi, Singapore: 2008, p. 471-472. Disponível em: http://www.stiba-malang. com/uploadbank/pustaka/RM/QUALITATIVE\%20METHOD\%20SAGE\%20ENCY. pdf. Acesso em: 10 jun. 2016.

BURNS, E. Developing Email Interview Practices in Qualitative Research. Sociological Research Online, 15 (4) 8, 2010. Disponível em: http://www.socresonline. org.uk/15/4/8.html. Acesso em: 10 jun. 2016.

CHASIN, C. J. D. L. Amoeba in their habitat - the asexual community: an ecological and discursive perspective. 2009. Disponível em www.asexuality.org. Acesso em: 10 out. 2010.

COOK, K. E. In-depth interview. In: GIVEN, L. M. (org.) The Sage Encyclopedia of qualitative research methods. Volumes 1 \& 2, Los Angeles, London, New Delhi, Singapore: 2008, p.422-423. Disponível em: http://www.stiba-malang.com/uploadbank/pustaka/RM/ QUALITATIVE\%20METHOD\%20SAGE\%20ENCY.pdf. Acesso em: 10 jun. 2016.

DICIONÁRIO INFOPÉDIA DA LÍNGUA PORTUGUESA [on line]. Porto Editora, 20032018. https://www.infopedia.pt/dicionarios/lingua-portuguesa. Acesso em: 07 mai. 2018.

DUARTE, R. Pesquisa qualitativa: reflexões sobre o trabalho de campo. Cadernos de Pesquisa, n. 115, março/2002, p. 139-154. Disponível em: http://unisc.br/portal/upload/ com_arquivo/pesquisa_qualitativa_reflexoes_sobre_o_trabalho_de_campo.pdf. Acesso em: 10 jun. 2016.

DUARTE, R. Entrevistas em pesquisas qualitativas. Educar, Curitiba, n. 24, 2004, p. $213-$ 225. Disponível em: http://www.scielo.br/pdf/er/n24/n24a11.pdf. Acesso em: 10 jun. 2016.

EGAN, J. E-mail interview. In: GIVEN, L. M. (org.) The Sage Encyclopedia of qualitative research methods. Volumes 1 \& 2, Los Angeles, London, New Delhi, Singapore: 2008, p. 244. Disponível em: http://www.stiba-malang.com/uploadbank/pustaka/RM/ QUALITATIVE\%20METHOD\%20SAGE\%20ENCY.pdf. Acesso em: 10 jun. 2016.

FOUCAULT, M. História da Sexualidade I: a vontade de saber. Tradução Maria Thereza da Costa Albuquerque e J. A. Guilon Albuquerque. 16ª ed. Rio de Janeiro: Edições Graal, 2005.

FRASER, M. T. D.; GONDIM, S. M. G. Da fala do outro ao texto negociado: discussões sobre a entrevista na pesquisa qualitativa. Paidéia, 14 (28), 2004, p.139 -152. Disponível 
em: http://www.scielo.br/scielo.php?script=sci_arttext\&pid=S0103-863X2004000200004. Acesso em: 10 jun. 2016.

GAGNON, J. H. Uma interpretação do desejo - ensaios sobre o estudo da sexualidade. Rio de Janeiro: Garamond, 2006.

GIDDENS, A. As Consequências da Modernidade. São Paulo: Editora UNESP, 1991.

GIL, A. C. Métodos e técnicas de pesquisa social. São Paulo: Editora Atlas, 2008. Disponível em: https://ayanrafael.files.wordpress.com/2011/08/gil-a-c-mc3a9todos-etc3a9cnicas-de-pesquisa-social.pdf. Acesso em: 10 jun. 2016.

HEILBORN, M. L.; AQUINO, E. M. L.; BOZON, M.; KNAUTH, D. R. (org.) O aprendizado da sexualidade - reprodução e trajetórias sociais de jovens brasileiros. Rio de Janeiro: Editora Fiocruz/Garamond, 2006.

HUNT, N.; McHALE, S. A Practical Guide to the E-Mail Interview. Qualitative Health Research. Sage Publications, Volume 17, Number 10, December 2007.

MARTINS, H. H. T. S. Metodologia qualitativa de pesquisa. Educação e Pesquisa, São Paulo, v. 30, n. 2, maio/ago. 2004, p. 289-300. Disponível em: http://www.scielo.br/pdf/ ep/v30n2/v30n2a07. Acesso em: 10 jun. 2016.

MARTUCCELLI, D. Grammaires de l'individu. Mesnil-Sur-L'Estrée, France, Éditions Gallimard, p. 343-386, 2002.

MEHO, L. I. E-Mail Interviewing in Qualitative Research: A Methodological Discussion. Journal of the American Society for Information Science and Technology, 57(10), 2006, p. 1284-1295. Disponível em: http://eprints.rclis.org/8377/1/email-interviewing.pdf. Acesso em: 10 jun. 2016.

OLIVEIRA, E. R. B. de. "Minha vida de ameba": os scripts sexo-normativos e a construção social das assexualidades na internet e na escola' 2014223 f. Doutorado em EDUCAÇÃO Instituição de Ensino: UNIVERSIDADE DE SÃO PAULO, São Paulo Biblioteca Depositária: FEUSP.

OPDENAKKER, R. Advantages and disadvantages of four interview techniques in qualitative research. FQS Forum: Qualitative Social Research. Volume 7, Nr. 4, Art 11 - Semptember, 2006. Disponível em: http://www.qualitative-research.net/index.php/fqs/ article/view/175/391. Acesso em: 10 jun. 2016.

SEFFNER, F. Derivas da masculinidade: representação, identidade e diferença no âmbito da masculinidade bissexual. 260 p. Tese (Doutorado em Educação). Faculdade de Educação, Universidade Federal do Rio Grande do Sul, 2003

SELWYN, N.; ROBSON, K. Using e-mail as a research tool. Social Research Update. Issue 21, Summer 1998. Disponível em: http:/ / sru.soc.surrey.ac.uk/SRU21.html. Acesso em: 10 jun. 2016.

WEEKS, J. O corpo e a sexualidade. In: LOURO, Guacira L. (org.). O corpo educado pedagogias da sexualidade. Belo Horizonte: Autêntica, p. 35-82, 2001. 


\section{NOTAS}

${ }^{1}$ Pesquisa GRAVAD - Gravidez na adolescência: estudo multicêntrico sobre jovens, sexualidade e reprodução no Brasil (HEILBORN et al., 2006).

${ }^{2}$ No hinduísmo, avatar representa a materialização de um ser divino na Terra. Na internet, avatar refere-se a uma representação gráfica de um usuário em comunidades virtuais, redes sociais, fóruns de debate e jogos. Dicionário Infopédia da Língua Portuguesa [on line]. Porto Editora, 2003-2018. [consulta 29/04/2018]. Disponível em: www.infopedia.pt/dicionarios/ lingua-portuguesa/avatar.

${ }^{3}$ Aplicativo que possibilita chamadas por voz e/ou vídeo - entre outros recursos - via computador ou dispositivos móveis.

${ }^{4} \mathrm{O}$ mesmo roteiro semiestruturado de perguntas foi utilizado para todos os entrevistados, sendo que no roteiro para os entrevistados por e-mail, as perguntas traziam maior grau de detalhamento, evitando mal-entendidos que pudessem gerar atrasos nas respostas.

${ }^{5}$ Todos os entrevistados - nas duas modalidades de entrevista - preencheram um cadastro com informações que possibilitaram a elaboração do perfil do conjunto de participantes. Além disso, todos os participantes entrevistados por e-mail preencheram, assinaram e nos enviaram por correio o Termo de Consentimento Livre e Esclarecido, concedendo autorização para a utilização de suas entrevistas na pesquisa. Desta forma, pudemos manter um cadastro com nomes e endereços, entre outras informações, de todos os entrevistados.

Submetido: $23 / 02 / 2018$

Aprovado: 11/06/2018

Contato:

Elisabete Regina Baptista de Oliveira

Rua Antônio Tavares, 300, Ap. 54

São Paulo|SP|Brasil

CEP 01.542-010 